\title{
Goals and Accountability for Ministry Effectiveness: Insights from Psychological Science
}

\section{DAVID R. DUNAETZ \\ Azusa Pacific University}

\begin{abstract}
In this overview of what psychological science has discovered about goal setting, we will see that goal setting tends to make people more productive. This essay examines the conditions under which goal setting is most effective, as well as the situations where goal setting can be dangerous. Studies of goal-setting theory have found that job performance increases when people have challenging but specific performance goals. The mechanisms that cause goal setting to lead to greater effectiveness are just as present in Christian ministry as in any other kind of work. Also the dangers associated with goal setting are especially relevant in Christian contexts.

Key Words: ability, accountability, church planting, dangers in goal-setting, effectiveness, effort, evangelization, feedback, formulation, goal commitment, goal ownership, goal-setting theory, job performance, language-learning, motivation, outcome expectancies, performance, planning, psychological science, rewards, selfefficacy, strategy, team context, training.
\end{abstract}

David R. Dunaetz, M.A., M.S., M.Div., Th.M., Magisterère, Assistant Professor of Psychology, Azusa-Pacific University, California, USA, and former church planter in France.

Here are the stories of three hypothetical Christian workers who serve with evangelical organizations. Each of their organizations promotes itself as committed to fulfilling the Great Commission among the least evangelized. 
Kumar. For twenty years Kumar has worked more or less as a church planter. His sending organization has broad principles of accountability concerning ethics, money, and doctrine. However, the organization demands little concerning ministry or strategy, leaving it up to the individual Christian workers to do their best as the Spirit leads. Kumar has worked in several young, subsidized churches during his career, none of which have become quite ready to fully support themselves. Some years the churches have grown; other years have been more difficult. Kumar is confident that eventually these churches will become self-supporting. He has served faithfully during this time, is much appreciated by the people whom he serves, and is looking forward to retirement after several more years of this type of ministry.

Gopinathan. Like Kumar, Gopinathan has served with his organization for about 20 years. He joined at a time when awe-inspiring church planting goals for the year 2000 were being promoted by his organization. For the first few years of his ministry, he worked endlessly towards accomplishing these goals and was encouraged by the progress made, although it was far less than what everyone had envisioned. As the year 2000 approached, it became clear that the goals would not be achieved. Both pastors and other Christian workers in the church association were somewhat burned out with goal setting and disappointed that they failed to reach their goals. Since then, there has been little emphasis on goal setting. Gopinathan has continued to pastor the same church plant for over 10 years and is confident that one day the church will support its own local leadership.

Santosh. Like the others, Santosh has been with his organization for about 20 years. Early in his ministry, he began working with a team that had a well-defined strategy and would hold its members accountable for making progress on this strategy. They would meet regularly, between one and four times a month, to support one another, to hold one another accountable, to evaluate the progress made in the ministry, and to determine new goals to accomplish before their next meeting. After the team's first church plant was firmly established, Santosh formed and led another team which followed the same pattern. Santosh has now started three churches and has a goal to start three others before he retires. 
These three examples illustrate three common approaches to goal setting in Christian organizations. Some Christian workers pay little attention to goals. Others have focused on goals in the past, but now see little value in them. Other Christian workers regularly set goals and hold one another accountable for accomplishing them. In this overview of what psychological science has discovered about goal setting, we will see that goal setting tends to make people more productive. It can make the difference between the results that Kumar and Gopinathan have experienced and those that Santosh has experienced. We will examine the conditions under which goal setting is most effective, as well as the situations where goal setting can be dangerous.

The most complete and thoroughly tested theory of how goals affect motivation and job performance is called goal-setting theory, developed by Gary Latham of the University of Toronto and Edwin Locke of the University of Maryland (Locke \& Latham, 1990, 2002). The most robust finding from studies of goal-setting theory is that job performance increases when people have difficult (but doable) specific performance goals. These results have been confirmed by studies of over 40,000 individuals in North America, Europe, Asia, and the Caribbean. In both laboratory and field settings, these studies have found that there is more than a $90 \%$ chance that any individual will accomplish more with difficult, specific performance goals than if the individual is simply encouraged to do one's best. These results have proven themselves true for activities as diverse as logging, typing speed, university teaching, and engineering (Latham, 2000). As we shall see, the underlying mechanisms that cause goal setting to lead to greater effectiveness are just as present in Christian ministry as they are in any other kind of work. We shall also see that the dangers associated with goal setting are especially relevant in Christian contexts. But first, let us examine the relationship between motivation, goal setting, and performance.

\section{Goal Setting, Motivation, and Performance}

The simplest way to predict the quality of a person's performance on a task is with the following equation (Heider, 1958):

$$
\text { Ability } \times \text { Motivation }=\text { Performance }
$$


This means that, given two people with equal ability, the person who is more motivated will perform better than the person who is less motivated. For example, suppose there are two English-speaking Christian workers studying a local language in order to effectively minister among a certain people group. These two workers are equally gifted in language learning. If one of them has few or no English-speaking friends in her new context, she will be highly motivated to learn the local language in order to meet her social needs and to become effective in ministry. However, if the other Christian has many English-speaking friends around her, she may have fewer social needs left unmet and will probably be less motivated to learn the local language. This Christian worker is likely to make less progress in language-learning than the one who is more motivated.

It is fairly easy to understand how ability influences performance. If a person does not have the ability to do something, the person is literally unable to do it. The effects of motivation, on the other hand, are a bit more difficult to understand. Motivation affects behavior and performance because it influences the choices people make, the effort that they expend trying to achieve the goals they have chosen, and the persistence that they demonstrate when faced with obstacles (Bandura, 1997; Latham, 2000). Both environmental and personal factors influence people's motivation. Goal setting may be one of these factors. Let us examine how goal setting may influence motivation and, thus, performance (Figure 1). 


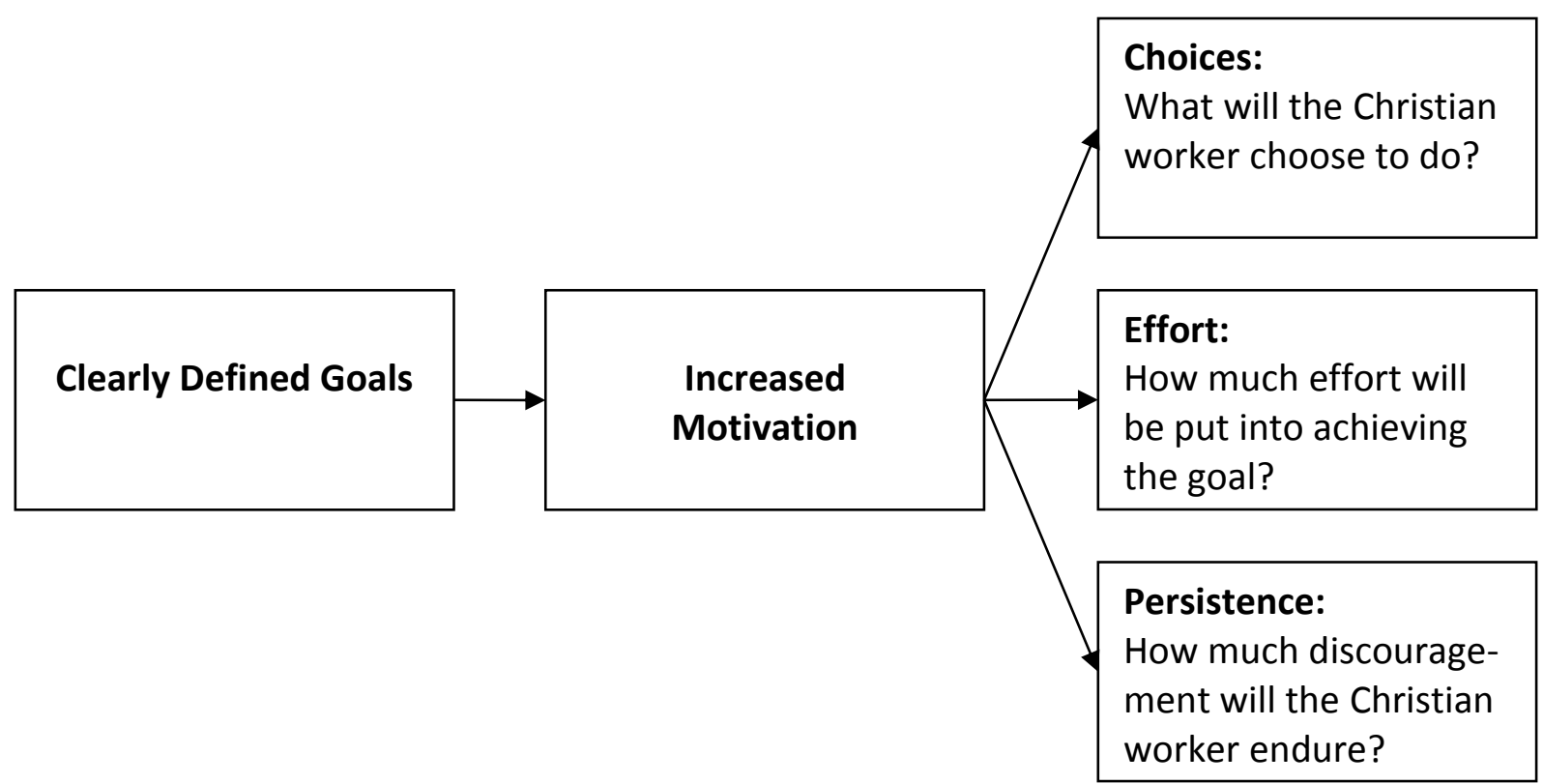

Figure 1: The influence of goals on motivation and associated behaviors

When people have ownership of goals, this influences the choices they make. If a Christian worker has the goal of having 15 conversations with non-Christians per week, he will make choices in his daily schedule that will enable him to have more of these conversations. He might have to choose to spend less time writing a prayer letter or surfing the internet to find the perfect illustration for an upcoming sermon. Since he wants to achieve his goal, he will be more likely to say no to activities that do not contribute to achieving the goal and more likely to say yes to activities that enable him to achieve it, such as going to a local city council meeting or some other event where he can have a conversation with non-Christians.

When people have ownership of goals, they will expend more effort on a task. If our Christian worker has a specific goal of having 15 conversations with non-Christians per week, he'll keep trying to talk to non-Christians until he's reached that goal. If he simply has a vague, general desire to speak to non-Christians, speaking to one or two per week might make him feel quite satisfied. However, if he has a specific, challenging goal, he will spend more effort in order to achieve it. 
Goals also lead to greater persistence when encountering difficulties. If our Christian worker is insulted by the second non-Christian he speaks to this week, he might spend a lot of time during the remaining part of the week on his next prayer letter and sermon preparation for Sunday, especially if he simply has a vague, general goal of having conversations with non-Christians. However, if he has the more specific, challenging goal of speaking to 15 , he will be more likely to persist in his efforts to achieve his goal.

These relationships between goals, motivation, and behavior are not simply theoretical. Goal setting has been experimentally demonstrated many times to increase motivation and to influence choice of activity, effort, and persistence (Latham \& Locke, 1991). This is all the more reason for Christian workers, as stewards of the resources that God has given, to take goal setting seriously.

In addition to their direct influence on choices, effort, and persistence, goals also lead to greater expenditures of cognitive effort as a person seeks to discover new and diverse ways to attain his or her goals. Our Christian worker with the goal of 15 conversations per week with non-Christians will spend more time thinking about what his options are for how to achieve this goal. He will put more effort into figuring out what his best choices are. If he meets opposition, he will spend more effort figuring out how to work around the opposition in order to achieve his goals.

So, as a result of increased motivation for the specific tasks necessary to accomplish goals, Christian workers will tend to accomplish more than if they did not have goals. They will choose activities that contribute the most to achieving their goals. They will do more planning and spend more time trying to achieve their goals. They will be more persistent when facing opposition in order to hit the target for which they are aiming. They will increase their cognitive effort in order to achieve their goals.

It is fairly easy to see that goal setting is an excellent way to increase Christian workers' motivation and to thus increase their effectiveness. However, not all goal setting efforts are equal. We shall now examine under which conditions goals are the most useful.

\section{When Are Goals Most Useful?}


There are several conditions that are necessary for goals to be the most useful. If these conditions are not met, goal setting may be mere wishful thinking, or even detrimental to the work we want to accomplish. Christian workers who have a negative attitude toward goals, such as Gopinathan whom we met above, often have had negative experiences with goals that have not met these criteria.

Correct Formulation. First of all, goals need to be correctly formulated. Specifically, they must be formulated to be doable, specific, and challenging. Ministry goals must also be in alignment with both the Christian workers' and the supervising organizations' larger, overarching goals. In addition, they must be formulated in a way that focuses on what the Christian worker should do, not what other people should do.

Goals must be doable. This was one of the problems with church planting and evangelism goals associated with the year 2000 (e.g. Montgomery, 1989). Sending organizations often adopted goals that assumed a conversion rate and a church planting rate that was much higher than what they had been experiencing. These goals were justified by a strong faith in God. However, if God has not acted a certain way in the past, it is not especially wise to assume that he will act differently in the future simply because we believe he will act differently. Perhaps faith in God should make us say that we believe God will continue to act as he has in the past where godly people have wholeheartedly served him. We cannot predict what God will do. Our goals need to be doable by us. If we choose goals that are not realistic or feasible, we risk the discouragement that comes from overconfidence induced failure.

Goals must be specific. For a goal to be useful, its accomplishment or nonaccomplishment must be clearly discernible. Specific goals almost always lead to higher results than general goals such as "Do your best." (Latham \& Locke, 1991; Latham \& Seijts, 1999). Experiments indicate that if production managers are given the goal of "doing their best," to reduce production errors, they will work less hard than if they are given the specific goal of reducing errors by $5 \%$ (Heath, Larrick, \& Wu, 1999). Having a general goal allows people to believe that they have done what is necessary, even if their activities have not accomplished anything. Objective, specific goals are necessary to determine if progress is truly being made. Specific goals enable Christian workers to objectively determine if they have accomplished what they wanted to. 
Goals must be challenging. In general, people put as much effort into achieving goals as necessary (Latham, 2000). If a goal is not very challenging, it provides little motivation to go beyond what one would do otherwise; a Christian worker would not need to expend much effort to achieve it. In addition, unchallenging goals do not lead to a sense of accomplishment; to the contrary, they encourage satisfaction with minimal results. For example, suppose the family of a Christian worker typically invites two to three families per month to their home for a meal. If the family sets a goal of inviting two families per month to their home for a meal, this goal will not provide the motivation for them to do anything differently, since they are already achieving it.

Goals must be in alignment with larger, overarching goals. If a goal is doable, specific, and challenging, it will tend to be fairly narrow in scope. However, God's will is often expressed in broader purposes, such as loving him or loving people. For example, "The goal of this commandment is love, which comes from a pure heart and a good conscience and a sincere faith" (I Tim. 1:5). Similarly, a sending organization might have overarching goals such as reaching unreached people groups or economic development. For this reason, it is important to make sure that the doable, specific, and challenging goals that Christian workers set for themselves are in agreement with, and contribute to, the broader, overarching goals defined by God and their organizations. When the two types of goals are not compatible, difficulties occur. For example, in order to accomplish his goals, a Christian worker might develop an evangelization strategy that falls short of the ethical standards revealed in God's Word. Although God might use this strategy for his glory (Phil. 1:14-18), it is far better to have goals that are accomplished through a strategy that reflects his ethical standards (I Cor. 9:27).

Goals must focus on the behavior of the Christian worker, not the behavior of others. A Christian worker's ultimate goal might be to see God glorified through many people turning to Christ. It might be tempting to set a goal of 1,10,100, or 1000 confessions of faith per year, depending on the context. However, confessions of faith and true repentance depend on much more than simply what the Christian worker does. A better goal would be formulated so that its accomplishment or non-accomplishment would depend only on the Christian worker, for example, distributing 1000 Bible study invitations per month. If we choose specific goals that depend on others' behavior (such 
as repentance, baptisms, etc.), whether or not these goals are accomplished is beyond our control, a condition which may result in either frustration or minimal motivation to change our own activities to accomplish them.

Goals need to be formulated correctly in order to be useful. They should be doable, specific, challenging, and in alignment with what God and one's organization desires. In addition, their accomplishment should be dependent on what the Christian worker can do, not on what others must do. Correctly formulated goals will be even more effective when accompanied by feedback and accountability.

Feedback and Accountability. To insure that goals are a positive motivational force to focus on what is most important, Christian workers need to receive feedback concerning how well they are accomplishing their goals. This is most easily accomplished by being accountable to someone they trust.

An oft sited organizational proverb is "That which gets measured gets done." When someone in an organization measures something, it sends a message that what is measured is important. If a goal is used as a point of reference, feedback concerning to what degree the goal has been accomplished can increase Christian worker motivation by indicating how much effort will be required to accomplish the remaining parts of the goal. If the feedback indicates that the goal has been accomplished (and if the goal has been challenging), this will lead to satisfaction with one's work which leads to a positive sense of pride in its accomplishment (Latham, 2000). For the Christian worker who believes that the goal was a reflection of God's will, receiving feedback indicating that the goal has been accomplished will be a subject of praise while feedback indicating that the goal is not yet accomplished will help the Christian worker focus his or her efforts on the task. It may also provide information indicating that either the goal or the strategy should be changed. Feedback provides information to Christian workers about what they should stop doing, what they should continue doing, and what they should start doing.

It is important that the person who provides feedback to the Christian worker, or who goes over the feedback with him or her, be someone who is trusted. A close friend and team member would be optimal. Receiving feedback can be threatening; feedback often includes information that the Christian worker has failed, at least temporarily, in his 
or her task. If the Christian worker feels judged, belittled, or unappreciated, the feedback will be a source of discouragement, which is not always an effective motivator. For feedback to be maximally effective, it is not enough for it to come from an administratively appointed supervisor. It needs to come from a person that the Christian worker trusts; such a relationship cannot be created by a hierarchy decreed by an organizational decision. Such trust can only come from a history of positive, supportive interactions with a person. This type of history is an important building block of close friendships and solid teams. Being held accountable by someone whom one trusts and admires is not painful as are most performance reviews (Coens \& Jenkins, 2000), but is a joy as "iron sharpens iron" (Prov. 27:17).

Goal Commitment. If Christian workers are not committed to their goals, the goals will have no effect on their ministry (Latham, 2000). If goals are assigned to them, or even if they set their own goals, an administrative duty has perhaps been performed, but without a personal commitment to accomplish them, these goals would essentially be a waste of time. There are two main mechanisms by which people become committed to goals: positive outcome expectancies and increased self-efficacy (Bandura, 1977; Latham, 2000; Shell, Murphy, \& Bruning, 1989). Both of these can be strongly influenced by supervisors and coworkers and are among the most important ways that Christian workers can encourage one another to be more productive.

Positive outcome expectancies refer to rewards, whether tangible or intangible, that are expected when goals are accomplished. For example, seeing a young man come to Christ after developing a close relationship with him would be reward for one's evangelistic efforts. If a Christian worker expects that at least one person will come to Christ due to an evangelistic activity, this positive expectancy will motivate him or her to be more committed to the goal and to pour more effort into making sure that the activity occurs. However, if the Christian worker has negative expectancies (e.g. no one will come to Christ and there will be no other benefit to organizing the activity), the Christian worker's goal commitment and resulting motivation will be much lower. Thus an important aspect of motivating Christian workers is to ensure that they have positive outcome expectancies for their goals. 
There are several ways that these positive expectancies can be created in order to increase goal commitment. First, emotionally charged, positive statements can be made by the organization's leaders about the goal. This can range from "encouragement" to "hype" depending on the veracity of the statements made. This underlines the importance of research in missiology. Leaders need as much information as possible, both biblical and experiential, as to what is effective and what is not effective in achieving the various goals that they promote.

Secondly, groups and teams can create their own rewards for accomplishing goals in order to increase their goal commitment. If several Christian workers within a team complete their outreach goals, the others may reward them with encouragement, praise, and emotional support, perhaps even providing a symbolic reward such as an award or public recognition. This is an especially important function of team leaders and other leaders within a Christian organization.

A third way of increasing positive expectancies and goal commitment is to observe successful others achieving similar goals and the positive results that they experience. If Pastor Gupta observes Pastor Singh passing out tracts that end up bringing people to the Lord, Pastor Gupta will develop positive expectancies for distributing tracts. Pastor Gupta will be more committed to tract distribution after observing Pastor Singh's success. This does not mean that Pastor Gupta will necessarily have the same success, but he will be more committed to the goal, and hence more motivated to work hard to achieve it, if he believes, based on his observations, that his efforts will have a positive payoff.

Besides positive outcome expectancies, goal commitment can also be increased by greater self-efficacy. Self-efficacy is the task specific belief that "I can do it" or "I can make it happen" (Bandura, 1977, 1997; Latham, 2000). This is different from positive outcome expectancies which are based on the belief "If I do it, good things will happen." Self-efficacy reflects beliefs about one's own capabilities. If Christian workers believe that they can accomplish a goal, they will be much more committed to it than if they do not believe they are capable of accomplishing it. Without a sense of self-efficacy concerning the goals in question, there is little chance that the motivation of a Christian worker will increase with goal setting. 
There are several ways that self-efficacy can be increased, all of which can be used by Christian organizational leaders and administrators to help those under them grow in goal commitment. First of all, training will increase self-efficacy, whether it be in the local language, in evangelism techniques, or any other domain that relates to goal accomplishment. If a Christian worker is unsure of possessing the skills necessary to accomplish a goal, training, if available, will make the goal more feasible.

Second, modeling will increase a person's sense of self-efficacy. For example, a Christian worker might feel completely incompetent to meet with a civic leader to explain his purposes for living in a community. However, if he accompanies someone else who is already comfortable with such a meeting, the Christian worker will gain knowledge and confidence; the next time such a meeting is necessary, he will be more likely to organize the meeting himself, having a greater sense of self-efficacy.

Third, goal commitment can be increased via greater self-efficacy through persuasion and encouragement, especially from a high status, respected other. If this high status, respected person (quite often an older male) expresses confidence in the Christian worker concerning a task, the Christian worker is more likely to feel competent than without this encouragement. People want to live up to others' expectations and to not disappoint them.

Thus we have examined several conditions that must be met for goals to be effective in increasing motivation in Christian workers. Goals need to be formulated correctly; they should be doable, specific, challenging, in alignment with larger goals, and based on the Christian worker's actions, not the actions of others. Goals also need to be accompanied by feedback and accountability. Finally, we saw that Christian workers must buy into the value of the goals; such goal commitment can be increased through positive outcome expectancies and increased self-efficacy. We will now examine the darker side of goals. Under what conditions can goals be dangerous?

\section{When Are Goals Dangerous?}

We have already hinted at several possible dangers of goals. We will examine two in detail. Goals can be dangerous when learning should take precedence over strategizing (Earley, Connolly, \& Ekegren, 1989; Kanfer \& Ackerman, 1989) and when 
there is an overemphasis on goals without having a comprehensive strategy.

Goal Setting versus Learning. Setting goals implies that the basic route to success is known. If a Christian worker has a broad understanding of what it takes to plant a church in a given culture or to bring clean water to a remote village, goal setting is possible and would be an excellent strategy for helping the Christian worker stay focused on the project until completion, providing motivation to accomplish the necessary steps in a reasonable amount of time. However, if the Christian worker does not know how to plant a church in that culture or how to bring clean water to a village, the priority must be on learning how to do the task before setting specific, measurable goals.

This implies that goals can be dangerous if the best way to accomplish the Christian worker's overarching task is not known. If a Christian worker has a specific, difficult goal to accomplish, but that goal does not really contribute to the overall picture of what the Christian worker is supposed to accomplish, much time and effort can be wasted. Rather than trying to accomplish a specific goal, the Christian worker's efforts could be better used to research what is most likely to work, or to experiment with different approaches to see which is most effective. For example, suppose the only form of evangelism that has been used in some area is door to door visitation, and such visitation has yielded little notable fruit. Rather than setting a goal of how many doors to knock on this month, it is quite possible that Christian worker could make better use of his or her time by experimenting with different methods or finding out what others have used effectively in similar situations.

In situations where learning should be a higher priority than setting task related goals, setting goals for learning might be appropriate. For example, if a Christian worker is beginning language study, it would be more important to set goals concerning vocabulary to learn, classes to take, or the number of conversations to hold; it probably would not be appropriate to set goals concerning the organization of evangelistic activities or leadership development programs.

Goals Gone Wild: An Overemphasis on Goals. Lisa Ordonez of the University of Arizona and her colleagues have documented many examples of goal setting which have resulted in negative results (Ordonez, Schweitzer, Galinsky, \& Bazerman, 2009). 
The primary reason for these negative consequences is an overemphasis on goal setting. This overemphasis can lead to goals that are too narrow, too focused on short term results, too challenging, or which produce a culture of competition.

An example of goals which were too narrowly focused can be seen in the history of the Ford Pinto. Ford had the goal of producing a subcompact car for under $\$ 2000$ by 1970. They met this goal but neglected to consider broader goals such as media and consumer perceptions of safety. This eventually led to a recall and a reputation of being one of the worst cars of all times (Lienert, 2004). Similarly, goals that are too narrowly focused can occur in Christian organizations. Many Christian workers would see the Great Commission (Matt. 28:18-19) as the overarching purpose of their work. However, an overemphasis on evangelism goals may lead to insufficient attention being paid to discipleship. In order to prevent such an imbalance, a comprehensive strategy must be developed that will encourage goals in all domains necessary to accomplish the Great Commission in a given context.

Similarly, goals may be too focused on short term results to be maximally effective. An example comes from the world of taxi drivers (Ordonez, et al., 2009). Often taxi drivers set a monetary goal for each day and stop work once this goal is accomplished. On rainy days, this goal can be accomplished very quickly, while on sunny days it takes much longer. When taxi drivers focus only on the daily short term goals, they end up having lots of free time on rainy days and working very long hours when the weather is nicer. If they chose strategies with a longer time perspective, such as doubling or tripling their daily targets whenever there was bad weather, they would need to work fewer days per year and more taxis would be available when there is the greatest need for them.

A similar situation may occur in church planting when the Christian worker is focused on quickly empowering local believers to lead the church. If the leadership pool is weak, with few members that have or are able to learn leadership skills, it might be best in the long term to continue to focus on evangelism rather than leadership development. Focusing on short term goals in leadership development can lead to the installation of leaders who lack the respect of the local community and who have little skill to move a church forward. As the community grows, there will be a greater chance 
that some of its members will have the required abilities to learn leadership skills; once this is the case, church planters may begin to give more of a priority to leadership development.

If goals are too challenging, the person being held accountable for these goals may take too many risks or be tempted to act unethically (Ordonez, et al., 2009). If the goals are not fully accomplished, it can lead to discouragement and lower performance, even if what was accomplished was important and significant (Coens \& Jenkins, 2000). In church planting and other forms of Christian work, where failure and discouragement occur frequently, goals that are too challenging are a significant danger because the risk of attrition is so high (Hay, Lim, Blocher, Ketelaar, \& Hay, 2007). Goal setting must take place in the context of accountability relationships which provide more encouragement than discouragement when goals are not met. It is also important that all aspects of holding one another accountable are perceived to be fair if there is a power differential between the parties (Dunaetz, 2010).

Christian workers might be tempted to act unethically if the goals are too challenging and cannot be met otherwise. Christian folklore includes stories of Christian workers presenting numerical results of their efforts "evangelistically speaking," exaggerating their accomplishments to make themselves look better. Another example of unethical behavior might be using the "foot in the door" technique (Burger, 1999; Cialdini, 1993) with surveys to share the gospel; under the pretext of conducting serious research, Christian workers might take advantage of people's desire to contribute to a better understanding of society in order to make a gospel presentation. Although God might use gospel presentations done with questionable methods for his glory as was the case while Paul was in prison (Phil. 1:15-18), Christian workers need to follow Paul's example of seeking to share the gospel with only pure motives and without using any form of deception (I Thess. 2:3).

An overemphasis on goals might also create a culture of competition within a Christian organization (Ordonez, et al., 2009). Rather than focusing on humbly loving and serving God together, the focus can change to seeing who can accomplish the most. Comparing our work to that of others is a common way of evaluating the quality of our work (Festinger, 1954). However, when the focus slips from serving God to 
seeing who can do the most to get the glory associated with outdoing others, we no longer have acceptable motives (I Thess. 3:6) and we risk damaging relationships with the people to whom we are the closest (Tesser, 1988). The best way to prevent this is to maintain a close, personal relationship with the Lord, seeking pure motives and confessing our impure motives as sin (Ps. 51, I Jn 1:9). Another way to reduce the likelihood of this happening is for each Christian worker on a team to have personalized goals, making it difficult to compete against one another directly, but enabling each Christian worker to root for the other team members and be encouraged by the success of others (Cialdini et al., 1976). This is easiest if the team has a clear vision and strategy that it is trying to accomplish.

Although goal setting can energize a Christian worker to become more effective, we have seen that goals can be dangerous under certain conditions. When the best strategy is not known, learning should take precedence over goal setting. We have also seen that an overemphasis on goals can lead to a focus that is too narrow, a disregard for long term outcomes, discouragement and unethical behavior when the goals are too difficult, or a culture of competition within a team of Christian workers. Although these dangers are real, the benefits from goal setting as described previously are also real. It is therefore our duty to implement a goal setting strategy that glorifies the Lord in order to help Christian workers be more effective.

\section{Implementing a Goal Setting Program}

To increase Christian worker effectiveness through goal setting, we need to consider several practical issues. At what hierarchical levels should goal setting be implemented in a Christian organization? Who should determine goals, supervisors or Christian workers themselves? What kind of training is necessary to maximize the value of goal setting?

At what levels can goal setting be used? Goal setting can be used at all levels within a Christian organization, whether it be among board members or volunteers in the mail room. It is especially relevant whenever there is a group of workers functioning together as a team. This provides the context for developing and 
refining goals as well as for holding one another accountable for accomplishing the goals.

Teams function best when they have clarity of mission (Sundstrom, De Meuse, \& Futrell, 1990) partially because they are able to determine what goals should be set in order to accomplish their mission. So before setting goals, it is preferable that teams clarify exactly what they are trying to accomplish. Because tradition and resistance to change are so strong in all organizations (not just Christian ones; Piderit, 2000), having a clear mission statement for a team is essential. Without one, there is a tendency to maintain traditional practices rather than bring about change. If a team of Christian workers does not have a mission statement already, a good place to start is with the Great Commission (Matt. 28:18-19) which can be adapted to the team's specific context.

Even if a team has a mission statement, before it sets goals, it would be good to develop a strategy based on the best practices of others who have accomplished the same mission in a similar context. A strategy is a logical plan of what team members are supposed to do so that eventually the mission is accomplished, although the Holy Spirit may direct people to modify the strategy as things develop. Once a strategy is defined, and the roles of each team member are defined, goals may be set to encourage maximizing Christian worker effectiveness.

Who should set goals for Christian workers? Workers are generally more committed to goals and perform better when they participate in the goal setting compared to workers who are simply assigned goals by their supervisors (Erez, Earley, \& Hulin, 1985). This seems logical since participation would seem to increase motivation to accomplish goals. However, many real life studies have often found that performance often does not decrease when goals are assigned compared to when they are set through participation (e.g. Locke, Latham, \& Erez, 1988; Meyer, Kay, \& French, 1965). When supervisors carefully explain how the goals were developed and why they are important, workers are often just as motivated to accomplish them as if they participated directly in the goal setting. In pioneer contexts, most goals should probably be set by teams who know their context best. However, it is conceivable that young teams could benefit from goals set by a supervisor who has greater expertise, if the 
supervisor explains in detail why these goals are important and how they were chosen. These goals could serve as training until the young team develops enough expertise to set its own goals.

How Can Christian workers Learn to Set Goals? Goal setting is not a difficult concept and is easily understood by Christian workers. However, there may be little commitment to actually set goals because of past abuses (as in the case of Gopinathan above) or because of a tradition that does not emphasize goal setting or accountability (as in the case of Kumar above). An eight hour training session that has been successfully used among people who might be resistant to goal setting (Frayne \& Latham, 1987) is presented in Table 1, adapted for the context of a Christian organization.

\begin{tabular}{|c|c|c|}
\hline Hour & Topic & Content \\
\hline \multirow[t]{2}{*}{1} & Principles of Goal & Why goal setting works. \\
\hline & Setting & The expected results of goal setting. \\
\hline \multirow[t]{2}{*}{2} & Mission and Strategy & The importance of mission and strategy. \\
\hline & & $\begin{array}{l}\text { Small group discussion concerning teams' mission and } \\
\text { strategy. }\end{array}$ \\
\hline \multirow[t]{2}{*}{3} & Setting Specific & Characteristics of specific goals. \\
\hline & Goals & Small group discussions of appropriate goals. \\
\hline \multirow[t]{3}{*}{4} & Understanding What & Possible reasons for problems. \\
\hline & Prevents Goal & Small group discussions in teams. \\
\hline & Completion & \\
\hline \multirow[t]{2}{*}{5} & The Value of Setting & What would change if goals were met. \\
\hline & Goals & $\begin{array}{l}\text { Small group discussions concerning how the team } \\
\text { would change. }\end{array}$ \\
\hline \multirow[t]{2}{*}{6} & Accountability and & Methods of monitoring one's actions. \\
\hline & Self-Monitoring & How to use team accountability in an encouraging way \\
\hline \multirow[t]{2}{*}{7} & Maintaining High & Preventing relapses. \\
\hline & Quality Goals & Adjusting goals. \\
\hline 8 & Review & Review of main points. \\
\hline
\end{tabular}




\section{Questions and answers.}

\section{Table 1: An 8 Hour Training Program for Christian worker Training in Goal Setting}

\section{Conclusion}

Setting challenging goals in a team context is a relatively easy and inexpensive way to increase Christian worker effectiveness. By setting goals in team situations Christian workers can focus their energies in the direction they sense the Lord to be leading, doing so in a context of supportive accountability. Although goals can be misused, in most settings where the focus is on the larger picture of what Christ wants to accomplish, goal setting is a tool that Christian workers can use to better accomplish what they are called to do.

\section{References}

Bandura, A. (1977). Self-efficacy: Toward a unifying theory of behavioral change. Psychological Review, 84, 191-215.

Bandura, A. (1997). Self-efficacy: The exercise of control. New York, NY: Freeman.

Burger, J. M. (1999). The foot-in-the-door compliance procedure: A multiple-process analysis and review. Personality and Social Psychology Review, 3, 303-325.

Cialdini, R. B. (1993). Influence: The psychology of persuasion (rev. ed.). New York, NY: HarperCollins.

Cialdini, R. B., Borden, R. J., Thorne, A., Walker, M. R., Freeman, S., \& Sloan, L. R. (1976). Basking in reflected glory: Three (football) field studies. Journal of Personality and Social Psychology, 34, 366-375.

Coens, T., \& Jenkins, M. (2000). Abolishing performance appraisals. San Francisco, CA: Berrett-Koehler.

Dunaetz, D. R. (2010). Organizational justice: Perceptions of being treated fairly. In D. Baker \& D. Hayward (Eds.), Serving Jesus with integrity: Ethics and accountability in mission (pp. 197-221). Pasadena, CA: William Carey Library.

Earley, P. C., Connolly, T., \& Ekegren, G. (1989). Goals, strategy development, and task performance: Some limits on the efficacy of goal setting. Journal of Applied Psychology, 74, 24-33. 
Erez, M., Earley, P. C., \& Hulin, C. L. (1985). The impact of participation on goal acceptance and performance: A two-step model. The Academy of Management Journal, 28, 50-66.

Festinger, L. (1954). A theory of social comparison processes. Human Relations, 7, 117-140.

Frayne, C. A., \& Latham, G. P. (1987). Application of social learning theory to employee selfmanagement of attendance. Journal of Applied Psychology, 72, 387-392.

Hay, R., Lim, V., Blocher, D., Ketelaar, J., \& Hay, S. (2007). Worth keeping: Global perspectives on best practice in missionary retention. Pasadena, CA: William Carey Library.

Heath, C., Larrick, R. P., \& Wu, G. (1999). Goals as reference points. Cognitive Psychology, 38, 79-109.

Heider, F. (1958). The psychology of interpersonal relations. New York, NY: John Wiley \& Sons.

Kanfer, R., \& Ackerman, P. L. (1989). Motivation and cognitive abilities: An integrative/aptitudetreatment interaction approach to skill acquisition. Journal of Applied Psychology, 74, 657-690.

Latham, G. P. (2000). Motivate employee performance through goal-setting. In E. A. Locke (Ed.), The Blackwell handbook of principles of organizational behavior (pp. 107-119). Malden, MA: Blackwell Publishers.

Latham, G. P., \& Locke, E. A. (1991). Self-regulation through goal setting. Organizational Behavior and Human Decision Processes, 50, 212-247.

Latham, G. P., \& Seijts, G. H. (1999). The effects of proximal and distal goals on performance on a moderately complex task. Journal of Organizational Behavior, 20, 421-429.

Lienert, D. (2004). The worst cars of all times. Forbes, http://www.forbes.com/2004/2001/2026/cx_dl_0126feat.html.

Locke, E. A., \& Latham, G. P. (1990). A theory of goal setting and task performance. Englewood Cliffs, NJ: Prentice Hall.

Locke, E. A., \& Latham, G. P. (2002). Building a practically useful theory of goal setting and task motivation: A 35-year odyssey. American Psychologist, 57, 705-717.

Locke, E. A., Latham, G. P., \& Erez, M. (1988). The determinants of goal commitment. The Academy of Management Review, 13, 23-39.

Meyer, H. H., Kay, E., \& French, J. R. P. (1965). Split roles in performance appraisal. 143, 123129.

Montgomery, J. (1989). Dawn 2000: 7 million churches to go. Pasadena: William Carey Library. Ordonez, L. D., Schweitzer, M. E., Galinsky, A. D., \& Bazerman, M. H. (2009). Goals gone wild: The systematic side effects of overprescribing goal setting. The Academy of Management Perspectives, 23, 6-16. 
Piderit, S. K. (2000). Rethinking resistance and recognizing ambivalence: A multidimensional view of attitudes toward an organizational change. Academy of Management Review, 783-794.

Shell, D. F., Murphy, C. C., \& Bruning, R. H. (1989). Self-efficacy and outcome expectancy mechanisms in reading and writing achievement. Journal of Educational Psychology, 81, 91-100.

Sundstrom, E., De Meuse, K. P., \& Futrell, D. (1990). Work teams: Applications and effectiveness. American psychologist, 45, 120-133.

Tesser, A. (1988). Toward a self-evaluation maintenance model of social behavior. In L. Berkowitz (Ed.), Advances in experimental social psychology (Vol. 21, pp. 181-227). San Diego, CA: Academic Press. 